\title{
La crisis y el euro
}

La catástrofe que vive Europa proviene no solo del exceso de deuda pública y gobiernos mal comportados, sino también de un sistema financiero que vendió una quimera absurda: rentabilidades seguras por encima del desempeño de economías que crecian a tasas mediocres

conjunto de paises con diferentes niveles de desarrollo y politicas fiscales está su-
mergido en una crisis que ha afectado cada uno de sus miembros en forma discada uno de sus milembros en forma dispareja. Grecia, España e Italia no son Aleeuro se deprecie respecto al délar alyen, a vuan y a otros, de manera de estimular su sector exportador y asi enfrentar la crisis. Por el contario, Alemania está preocupada por las posibles consecuencias inflacionarias de una caída del euro: al contrario de estos paises, siempre ha mantenido sus cuentas fiscales ordenadas. En cambio Grecia, España e Italia han tenido politicas fiscales expansivas que significaron un aumento insostenible de su deuda pública El futuro del euro es incierto. El banco central europeo -que es muy "alemán para sus cosas- sigue pensando que Europa es un solo pais y por tanto el control otras palabras, la medicina de baja inflacoón para Europa es más amarga que en otros lugares porque hay paises que no la necesitan, es más: requieren de un poco de ella para activar sus decaidas economías. Entonces, si desean seguir con euro sin producir un colapso en algunas regiones ni aflojar la mano en el contro de la inflación, la solución es única y es que hacen los paises con sus provincias, estados 0 unidades administrativas: rescatar a todos los que están en crisis. Pero es exactamente en esto en lo que los europeos flaquean, y dejan de pensar com un solo pais.

Echar a los mal comportados es otra el caso de Grecia, pero claramente no solución para España, por ejemplo. Si ese pais, u otro de mediana importancia deja el euro, entonces es mejor volver a u contexto donde cada miembro de la unión tenía la libertad de implementar la política monetaria que necesitara.

En si, ese escenario no es una mala idea.
¿Por qué los paises deben amarrarse a una moneda común y perder grados de liber-

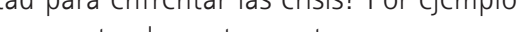
pave quiseram es formar una uno etaria comín con Argentina, Perú $y$ argentina en depreciar la moneda común porque Chile taviesa una situación económica complicada si el precio del cobre cae, pero no tener esa moneda común sin homogenizar las politicas fiscales respectivas con Argentina, Perú o Bolivia? Probablemente no. Sin embargo, Europa ya es lo que es. Desarmarla no es viable: vaya argumento que sería la desaparición del euro para que los mercados entraran en pánico.

HISTORIA ANTIGUA

ta actual crisis en Europa recuerda lo que sucedío con el patrón oro en la gran nismo no solo agudiź la crisis, sino que fue parte de la causa de la peor recesión de todos los tiempos. La lección fue una sola: en tiempos de crisis hay que deja de lado las ideas preconcebidas, soltar las amarras y buscar formas imaginativas de enfrentar la situación. En los años treinta as buenas ideas empezaron primero con politicas monetarias expansivas y luego con más gasto público, y se suponia que hacer eso era un pecado mortal. Y resulto. En la actualidad hay otros ingredientes que hacen que esta crisis en Europa tenga historia económica. La catástrofe proviene no solo del exceso de deuda pública y goeconomistas quieren enfatizar, sino también de un sistema financiero que vendio una quimera absurda: rentabilidades seguras por encima del desempeño de economias que por años han crecido a tasas mediocres. Si, ahora suena extraño, pero los inversionistas no solo de Europa, sino tambien de los Estados Unidos, creyeron que usando modelos financieros que entendian con alguna facilidad podian ganar inero. Bastaba con contratar algunos gras a dos estudiantes de los MBA o promáticos desiltriano en finanzas, o matemica par ganar musco dine vida acadéaue jamás antes se habia pensado. Erro los supuestos de los modelos financieLos no estaban malos: estaban muy pero muy, malos. El resultado es que la riqueza financiera se fue como el viento y con ello arrastró todo. Hasta la confianza en esos señores gritones que compran y venden cciones en las bolsas se esfumó. Ahora ente se amontona en las afueras de Wal Street y la City, no para comprar y vender,

sino para protestar.
Pero el euro no solo enfrenta problemas con los europeos. Los enemigos también aponeses y otros. El paupérrimo creciLos Estados Unidos ha hecho dólar también quiera caer respecto eras monedas. Obama y Bernanke neesitan desesperadamente un dólar màs débil no solo para revertir el déficit americano de cuenta corriente, sino para es miar su alicaido sector exportador. Y hay otra amenaza contra el euro: e pitalista lalgo que nos olvida sistemáticamente), debe tener fluctuaciones ciclicas. Si se abraza al sistema de mercado como orma de vida, se debe aceptar también la ncertidumbre y el desempleo. Esa es la aén se pierde y con se gana pero tam-

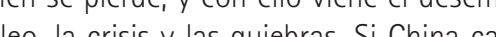
pleo, la cirsis y las quilebras. si China cae

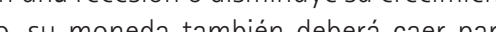
stimular el sector exportador. Si el dóla cae respecto al yuan, el yuan cae respecto del dólar: si el yen cae respecto del euro. sí el euro cae respecto del yen, si el euro cae respecto del dólar... al final ninguna Europa. ¿Querian una moneda estable? 
Ahi tienen al euro.

Dadas las circunstancias, las soluciones para Europa y el euro son extremas. Pri"pis": todos los miembos en un solo con la misma política fiscal Segundo: politica fiscal y monetaria expansiva: más inflación es necesaria en estos tiempos. Tercero: salvataje a todos los miembros por igual, moros y cristianos. Cuarto: implementación de políticas agresivas de empleo en todos los paises en crisis. Quinto: politicas macro prudenciales que controlen el crecimiento desmedido de credito privado. Sexto: regulación de los mercados financieros. Para Europa las crisis son malas. Existe una historia que dice que son caldo de cultivo del nacionalismo.

EN EL MUNDO EMERGENTE

Para los paises emergentes la situación

menor actividad mundial, un riesgo cie to

es la afluencia de capitales no solo de Eu-

ropa, sino de los Estados Unidos y Japón.

Los mismos modelos y personajes que antes alababan las bolsas de Atenas, Roma y Madrid, dirán que ahora las oportunidades de inversión están en las economias emergentes. Entonces ciertamente el euro caer en relación al peso y al real... iPor fin se se depreciará en relación a algo! Pero eso significa que ahora seremos nosotros los que sonaremos con la quimera financiera de plata fáci. ¿DCjaremos apreciar nuestras remos nuestra industriap exples y arvina?

Lo ocurrido en Europs no puede volves acurrir en las economís emergentes. Debemos usar las herramientas apropiad para controlar el exceso de flujos de captales, como los controles de capitales. Los bancos centrales deben moderar el crédito privado, cueste lo que cueste, y los gobiernos deben ahorrar las ganancias de los buenos precios de los commodities.

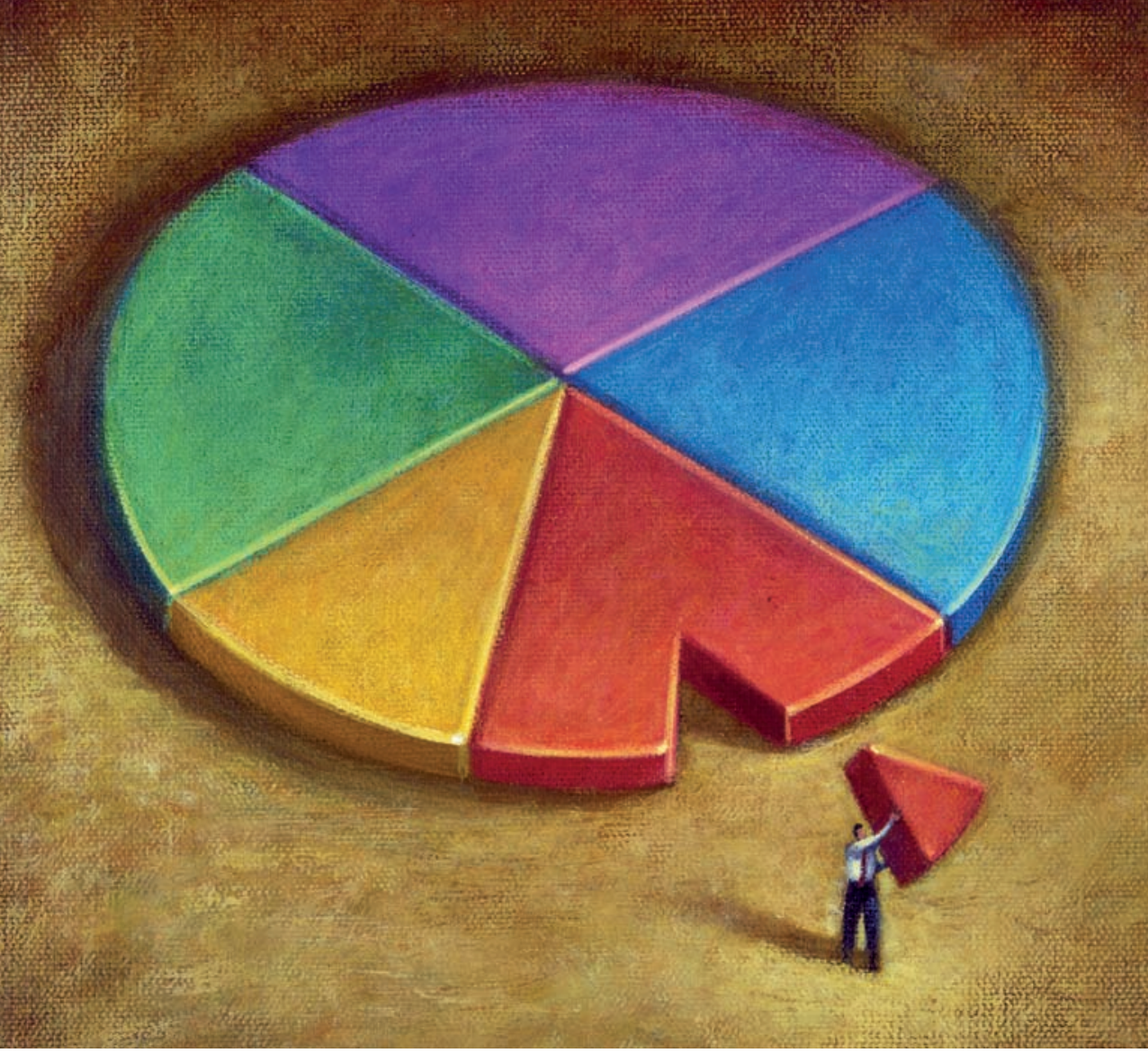

\section{¿Qué esperamos del Ingreso Etico Familar?}

Por Marcela Perticará

Doctora en Economia, Texas ACtM University.

Profesora Facultad de Economía y Negocios. UA

El Programa Ingreso Ético Familiar busca beneficiar a unas 620 mil personas aproximadamente unos 170 mil hogares, que viven en la indigencia. En este sentido, el programa es visto como una continuación del Programa Chile Solidario Chile. Sin de acción hacia el año 2001 eran las 225 mil familias más pobres inicios del año, por el lanzamiento del Programa de Asignación Social, que fue visto como un tibio comienzo de esta gran promesa de campaña. Luego, por el rechazo de las partidas prosupusstrias para el año 2012.

El programa entrega bonos por condición de vulnerabilidad y por cumplir con ciertos requisitos, pero también por lograr metas (educacionales, por ejemplo). tina. Desde Fumilias en Acción en Colombia, Bolsa Scola en Brasil, hasta el mismo Chile Solidario a principios de la década pasada El programa luce un andamiaje de condicionamientos más denso que estos, a la vez que, al menos en diseño, hace un mayor énfasis en el control de logros familiares e inclusive contempla un subsidio al trabajo femenino'.
Por el monto de los subsidios involucrados, uno a primera vista no esperaria que se constituyera en si en un beneficiarias. Pero si una failitias ingresos iguales a la linea de indigencia lograra obtener el máximo crédito del programa ${ }^{2}$ (aproximadamente unos 476 mil pesos anuales), esto pudier significar un incremento en sus ingresos anuales de aproximadamente $30 \%$. ¿Podria considerarse este ingreso familiar etico"? Posiblemente no, pero definitivamente para esta familia pode cuatro.

Podemos esperar que este program enga un gran impacto sobre salarios, empleo y otras medidas de bienesta del hogar? Evaluaciones anteriores de hile Solidario y otros de transferencias condicionadas no muestran grandes impactos en ingresos, aunque algunos casos se encuentran impactos levemente modestos sobre empleo y para Colombia si muestran que bs subsidios tienen un impacto positivo sobre consumo del hogar (alimentos ricos en proteinas y ropa y calzado pa los niños), a la vez que son altamente efectivos en aumentar la asistencia sistema educativo y reducir el trabajo sistich en hogar.

Hay que reconocer que el programa incrpora algunos elementos que si so su éxito, elementos que tal vez han esado ausentes de muchos otros programas similares en Latinoamerica, y este sentido reflejan mucho de lo que ha aprendido en esta materia en los úimos años. Primero, incorpora algunos elementos que reconocen la diversida de las familias, al menos en tamaño encosicion lascaria aminorar el efecto sustitucion que el subsidio público puede tener sobre el trabajo remunerado. Tercero, bien continúa usando como mecar de selección la ficha de protección social (mecanismo fácil de tergiversar), avanza en considerar otras fuentes de es) para on (cor el subsidio alsionafemenino.

Lo que no queda claro, aun cuando está presente en el discurso de la autoridad ${ }^{5}$, es como se incorpora el concepto de vulnerabilidad. El nivel de pobreza en Chile, bajo en relación al de otros paises lanoanericanos, esconde una alta no son pobres hoy has familias que caer en situación pueden fácilmente al enfrentar malas condiciones de salud y/o pérdida de empleo. Dados los alcances del programa (poco más de 600 mil personas), no es claro cómo pasar del discurso a la acción.

Este subsidio parece ir en el espiritu del propuesto por el Consejo Asesor Presidencia Trabajo y Equidad

hlo una familia biparental con dos niños, uno de ellos mayor de 6 años y con puntaje en la ficha de protección social inferior a 2.865

"Ver por ejemplo, Larrañaga, O., Contreras, pacto de Chile Solidario para la primera cohorte de participantes", PNUD-Chile. Hoces de la Guardia, F., Hojman, A. y 0 Larrañaga (2011) Evaluating the Chile Solidario proand the administrative databases" Estudios de Economia 38 (1), julio, pp. 129-168. "Attanasio, 0. y A. Mesnard (2006). “Th impact of a conditional cash transfer bia”, Fiscal Studies 27 (4) Dicionbe- Dp. 421-442. Attanasio, O. et al. (2006). "Chil education and work choices in the presen of a conditional cash transfer programme in rural Colombia", IFS Working Papers,
W06/01, Enero.

curio, Domingo 25 de Septiembre de 2011 Sección C, pag. 10. 